\title{
Corrigendum: Genome-Wide
} Association Studies for the Detection of Genetic Variants Associated With Daptomycin and Ceftaroline \section{Resistance in Staphylococcus aureus}

\author{
Robert E. Weber ${ }^{1}$, Stephan Fuchs ${ }^{2}$, Franziska Layer ${ }^{1}$, Anna Sommer ${ }^{1}$, \\ Jennifer K. Bender ${ }^{1}$, Andrea Thürmer ${ }^{3}$, Guido Werner ${ }^{1}$ and Birgit Strommenger ${ }^{1 *}$ \\ ${ }^{1}$ Department of Infectious Diseases, Robert Koch-Institute, Wernigerode, Germany, ${ }^{2}$ Methodology and Research \\ Infrastructure, Bioinformatics, Robert Koch-Institute, Berlin, Germany, ${ }^{3}$ Methodology and Research Infrastructure, Genome \\ Sequencing, Robert Koch-Institute, Berlin, Germany
}

Keywords: GWAS, daptomycin, ceftaroline, S. aureus, antibiotic resistance, PLINK, SEER

\section{A Corrigendum on}

Genome-Wide Association Studies for the Detection of Genetic Variants Associated With

OPEN ACCESS

Approved by: Frontiers Editorial Office,

Frontiers Media SA, Switzerland

${ }^{*}$ Correspondence:

Birgit Strommenge

strommengerb@rki.de

Specialty section

This article was submitted to Antimicrobials, Resistance and

Chemotherapy,

a section of the journal

Frontiers in Microbiology

Received: 26 March 2021

Accepted: 01 April 2021

Published: 27 April 2021

Citation:

Weber RE, Fuchs S, Layer F, Sommer A, Bender JK, Thürmer A, Werner $G$ and Strommenger B (2021)

Corrigendum: Genome-Wide Association Studies for the Detection of Genetic Variants Associated With

Daptomycin and Ceftaroline Resistance in Staphylococcus aureus.

Front. Microbiol. 12:686197.

doi: 10.3389/fmicb.2021.686197
Daptomycin and Ceftaroline Resistance in Staphylococcus aureus

by Weber, R. E., Fuchs, S., Layer, F., Sommer, A., Bender, J. K., Thürmer, A., et al. (2021). Front. Microbiol. 12:639660. doi: 10.3389/fmicb.2021.639660

In the published article, there was an error in affiliations. Instead of "Robert E. Weber ${ }^{1,2}$, Stephan Fuchs $^{3}$, Franziska Layer ${ }^{1,2}$, Anna Sommer ${ }^{1,2}$, Jennifer K. Bender ${ }^{1,2}$, Andrea Thürmer ${ }^{3}$, Guido Werner ${ }^{1,2}$ and Birgit Strommenger ${ }^{1,2 *}$

${ }^{1}$ Department of Infectious Diseases, Robert Koch-Institute, Wernigerode, Germany

${ }^{2}$ Methodology and Research Infrastructure, Genome Sequencing, Robert Koch-Institute, Berlin, Germany

${ }^{3}$ Methodology and Research Infrastructure, Bioinformatics, Robert Koch-Institute, Berlin, Germany", it should be

"Robert E. Weber ${ }^{1}$, Stephan Fuchs ${ }^{2}$, Franziska Layer ${ }^{1}$, Anna Sommer ${ }^{1}$, Jennifer K. Bender ${ }^{1}$, Andrea Thürmer ${ }^{3}$, Guido Werner ${ }^{1}$ and Birgit Strommenger ${ }^{1}$

${ }^{1}$ Department of Infectious Diseases, Robert Koch-Institute, Wernigerode, Germany

2 Methodology and Research Infrastructure, Bioinformatics, Robert Koch-Institute, Berlin, Germany

${ }^{3}$ Methodology and Research Infrastructure, Genome Sequencing, Robert Koch-Institute, Berlin, Germany"

The authors apologize for this error and state that this does not change the scientific conclusions of the article in any way. The original article has been updated.

Copyright (c) 2021 Weber, Fuchs, Layer, Sommer, Bender, Thürmer, Werner and Strommenger. This is an open-access article distributed under the terms of the Creative Commons Attribution License (CC BY). The use, distribution or reproduction in other forums is permitted, provided the original author(s) and the copyright owner(s) are credited and that the original publication in this journal is cited, in accordance with accepted academic practice. No use, distribution or reproduction is permitted which does not comply with these terms. 